\title{
Motivational Effects of Cannabinoids and Opioids on Food Reinforcement Depend on Simultaneous Activation of Cannabinoid and Opioid Systems
}

\author{
Marcello Solinas*,' and Steven R Goldberg' \\ 'Preclinical Pharmacology Section, Behavioral Neuroscience Branch, National Institute on Drug Abuse, Intramural Research Program, National \\ Institutes of Health, Department of Health and Human Services, Baltimore, MD, USA
}

\begin{abstract}
Strong functional interactions exist between endogenous cannabinoid and opioid systems. Here, we investigated whether cannabinoidopioid interactions modulate motivational effects of food reinforcement. In rats responding for food under a progressive-ratio schedule, the maximal effort (break point) expended to obtain $45 \mathrm{mg}$ pellets depended on the level of food deprivation, with free-feeding reducing break points and food-deprivation increasing break points. Delta-9-tetrahydrocannabinol (THC; 0.3-5.6 mg/kg intrapeitoneally (i.p.)) and morphine ( $1-10 \mathrm{mg} / \mathrm{kg}$ i.p.) dose-dependently increased break points for food reinforcement, while the cannabinoid CBI receptor antagonist rimonabant (SR-I4I7I6A; 0.3-3 mg/kg i.p.) and the preferential mu-opioid receptor antagonist naloxone (0.3-3 mg/kg i.p.) dose-dependently decreased break points. THC and morphine only increased break points when food was delivered during testing, suggesting that these treatments directly influenced reinforcing effects of food, rather than increasing behavior in a nonspecific manner. Effects of THC were blocked by rimonabant and effects of morphine were blocked by naloxone, demonstrating that THC's effects depended on cannabinoid CBI receptor activation and morphine's effects depended on opioid-receptor activation. Furthermore, THC's effects were blocked by naloxone and morphine's effects were blocked by rimonabant, demonstrating that mu-opioid receptors were involved in the effects of THC and cannabinoid CBI receptors were involved in the effects of morphine on food-reinforced behavior. Thus, activation of both endogenous cannabinoid and opioid systems appears to jointly facilitate motivational effects of food measured under progressive-ratio schedules of reinforcement and this facilitatory modulation appears to critically depend on interactions between these two systems. These findings support the proposed therapeutic utility of cannabinoid agonists and antagonists in eating disorders. Neuropsychopharmacology (2005) 30, 2035-2045. doi: I0.I 038/sj.npp. I 300720; published online 6 April 2005
\end{abstract}

Keywords: cannabis; opiates; progressive ratio; appetite; anorexigenic; obesity

\section{INTRODUCTION}

An impressive amount of data has been accumulated over the last 10 years on functional interactions between cannabinoid and opioid drugs, suggesting a strong crosstalk between endogenous cannabinoid and opioid systems (Manzanares et al, 1999; Tanda and Goldberg, 2003). Delta-9-tetrahydrocannibinol (THC), the main psychoactive ingredient in cannabis and marijuana, produces its behavioral effects by binding to cannabinoid CB1 receptors, while morphine, the main active ingredient in opium, produces its behavioral effects by binding to opioid

* Correspondence: Dr M Solinas. Current address: Laboratoire de Biologie et Physiologie Cellulaires, CNRS-6187, University of Poitiers, 40 Avenue du Recteur Pineau, Poitiers 86022, France, Tel: + 33549 366225, Fax: + 33549 4540 I4, E-mail: msolinas@intra.nida.nih.gov or marcello.solinas@ext.univ-poitiers.fr

Received 10 December 2004; revised and accepted 4 February 2005 Online publication: I 5 February 2005 at http://www.acnp.org/citations/ NPP02 I 50504058 I/default.pdf receptors. One of the reported behavioral effects of both cannabinoid and opioid agonists in humans and experimental animals is their ability to increase appetite and food consumption (Abel, 1975; Yeomans and Gray, 2002). Recently, the use of cannabinoid CB1 receptor agonists for this purpose was approved for patients with cancer and HIV (Croxford, 2003). The ability of cannabinoids and opioids to enhance food intake also has been demonstrated in animal models. For example, THC increases the intake of food (Williams et al, 1998) and sweet solutions (Gallate et al, 1999) in rats and, similarly, morphine enhances the intake of sweet solutions (Cooper and Kirkham, 1990; Gosnell and Levine, 1996).

Consistent with a role for endogenous cannabinoid and opioid systems in the regulation of appetite and food intake, blocking endogenous cannabinoid tone with the cannabinoid CB1 receptor antagonist rimonabant (SR-14716A) (Arnone et al, 1997; Colombo et al, 1998; Simiand et al, 1998; Freedland et al, 2000; McLaughlin et al, 2003; Thornton-Jones et al, 2004) or endogenous opioid tone 
with the opioid antagonist naloxone (Cooper and Kirkham, 1990; Gosnell and Levine, 1996) reduces intake of food or sweet solutions. In addition, these anorexigenic effects of rimonabant and naloxone have been found to be synergistic (Kirkham and Williams, 2001). Finally, the use of the cannabinoid CB1 antagonist rimonabant has been proposed as a medication for the treatment of obesity (Berry and Mechoulam, 2002) and is in its final phase III clinical trials (Fernandez and Allison, 2004).

It has been suggested that endogenous cannabinoid and opioid systems are linked to reward processes that mediate the incentive or hedonic value of food' such as the salience or palatability of food (Kirkham, 2003), and that the cannabinoid CB1 antagonist rimonabant reduces eating behavior by blocking these positive motivational processes, rather than limiting eating behavior by facilitating the negative control exerted by satiety processes. Studies investigating such control of food reward have focused on measuring the amount of freely available food or sweet solutions consumed or their patterns of consumption during given periods of time rather than the motivational value or reinforcing efficacy of given amounts of food (but see Gallate et al, 1999). Progressive-ratio schedules of food reinforcement were developed in the 1960 s to measure the amount of effort a subject will exert to obtain food (Hodos, 1961). With these procedures, the number of responses required to obtain reinforcement (eg a food pellet) progressively increases within a session until the individual stops responding, an end point referred to as the 'break point.' Although the break point may be affected by other variables, it is exquisitely sensitive to both the magnitude of reinforcement and the motivational state of the animal. Thus, it is widely considered a relatively direct measure of the efficacy or incentive value of a reinforcer under specific conditions. Progressiveratio procedures have been used extensively to study not only food but also the reinforcing effects of selfadministered drugs (Griffiths et al, 1975; Arnold and Roberts, 1997). Thus, progressive-ratio schedules provide valuable and direct procedures for the investigation of brain mechanisms underlying important aspects of the motivational effects of both food and drug reinforcement.

In this study, we investigated the effects of opioid and cannabinoid compounds and the interactions between opioid and cannabinoid systems on the effort foodrestricted Sprague-Dawley rats would expend to obtain food. Operant nose-poke responding reinforced by food pellet delivery under a progressive-ratio schedule was used as a measure of the motivational effects of food reinforcement. This procedure allowed us to measure the maximal effort animals expended to obtain food pellets (last ratio completed or break point) as well as the amount of food obtained in a session. After demonstrating the sensitivity of this procedure to food-deprivation and satiety conditions, the procedure was used to investigate the effects of THC, morphine, rimonabant, and naltrexone on foodreinforced behavior. In addition, the effects of combinations of THC and morphine with rimonabant and naloxone were studied to investigate the influence of interactions between cannabinoid and opioid systems on this food-reinforced behavior.

\section{MATERIALS AND METHODS}

\section{Subjects}

Twelve male Sprague-Dawley rats (Charles River, Wilmington, MA), experimentally naive at the start of the study and initially weighing 300-350 g, were used for all experiments. Rats were initially deprived to about $90 \%$ of their ad libitum body weight and, after the acquisition of food-reinforced responding, they were allowed to eat about $20 \mathrm{~g}$ of 'lab chow' food pellets (NIH07, NIH, Bethesda, MD) each day. Their body weight increased about $1 \mathrm{~g} /$ day for the first 3-6 weeks and then stabilized at about $380-400 \mathrm{~g}$. This level of food restriction resulted in stable baseline conditions throughout the duration of the experiment. Food was always given shortly after the end of the daily experimental session. Water was available ad libitum for all animals in their home cages. All rats were housed individually in a temperature- and humidity-controlled room and were maintained on a 12-h light/dark cycle; the lights were on from 0645 to 1845 . Experiments were conducted during the light phase. Animals used in this study were maintained in facilities fully accredited by the American Association for the Accreditation of Laboratory Animal Care (AAALAC) and all experiments were conducted in accordance with the guidelines of the Institutional Care and Use Committee of the Intramural Research Program, National Institute on Drug Abuse (NIDA), and National Institutes of Health and the Guidelines for the Care and Use of Mammals in Neuroscience and Behavioral Research (National Research Council, 2003).

\section{Food Reinforcement Apparatus and Procedure}

Experimental chambers $\left(30 \times 24 \times 29 \mathrm{~cm}^{3}\right.$, Coulbourn Instruments, Allentown, PA) were enclosed individually in sound-attenuation chests. Each experimental chamber had a metal grid floor, a recessed food tray, and two nose-poke holes in the right wall. A $4500-\mathrm{Hz}$ auditory stimulus was provided by a Sonalert (model \#628) operated at $8.75 \mathrm{~V}$. Each chamber was equipped with a food-pellet dispenser, which could deliver $45 \mathrm{mg}$ food pellets (F0021; Bioserv, Frenchtown, NJ) to the food tray. Illumination was provided by a shielded white light bulb (type \#1820) at all times, except during food delivery and time-out periods, when both the tone and the light were pulsed at a rate of $5 \mathrm{~Hz}$, with one stimulus on while the other was off. Experimental events were controlled by microcomputers using Med Associates interface and software (Med Associates Inc., East Fairfield, VT).

Food self-administration under the progressive-ratio schedule. Rats learned to respond for food during one to three sessions under an FR1 schedule. A single response in the left nose-poke hole immediately resulted in the delivery of one food pellet and also caused the house light to flash and a tone to pulse for $5 \mathrm{~s}$. During this 5-s time-out period, responding had no programmed consequences. Following the time out, the next response in the left hole was again reinforced. Responses in the nose-poke hole on the right side were recorded but never reinforced. Sessions lasted $1 \mathrm{~h}$ 
or until rats earned 100 pellets, whichever occurred first. In most cases, after the first day, rats earned more than 100 pellets in less than $30 \mathrm{~min}$, demonstrating that strong food self-administration behavior had been acquired. Following these initial sessions, rats were directly switched to the progressive-ratio schedule. Under the progressiveratio schedule of food reinforcement, the number of responses required to produce a food pellet increased with each successive food pellet. The steps of the exponential progression were the same as those previously developed by Roberts and colleagues (Roberts and Bennett, 1993) and previously used by Solinas et al (2003) for food reinforcement, based on the equation: response ratio $=\left(5 \mathrm{e} X^{(0.2 \times \text { infusion number })}\right)-5$, rounded to the nearest integer. Thus, the values of the steps were $1,2,4,6,9,12,15$, $20,25,32,40,50,62,77,95,118,145,178,219,268,328,402$, 492, 603, and 737. Sessions under the progressive-ratio schedule lasted until $5 \mathrm{~min}$ passed without a response, which, under basal conditions, occurred within $1 \mathrm{~h}$ as described in Solinas et al (2003). Responding was typically very high during the initial sessions and slightly decreased and stabilized within five to eight sessions. When stable baseline behavior was reached, test sessions started. Baseline responding was considered stable when the number of food pellets earned per session did not differ by more than $10 \%$ for three consecutive sessions. Between test sessions, there were at least two control sessions in order to reestablish baseline responding. Usually, rats immediately returned to the original baseline level of responding so that three tests could be conducted over a 2-week period. Sessions were conducted Monday to Friday and body weights were monitored weekly. First, tests were conducted to establish whether the break point was sensitive to food motivation by temporarily free feeding or food depriving the rats. For the free-feeding condition, rats were given free access to food from just after the last baseline daily session until the start of the next session. For the food-deprivation condition, rats did not receive any food pellets from just after the last baseline daily session until the start of the next session. Weight gain and loss were measured before the beginning of the session. After validating the progressive-ratio procedure by demonstrating its sensitivity to food-deprivation conditions, rats were returned to the original level of food restriction until behavior restabilized and tests with cannabinoid and opioid compounds were then started.

No food-delivery procedure. In order to prevent food delivery and consumption, the tygon tubing that normally connected the food-pellet dispenser to the tray was disconnected before the start of the session. In these conditions, all stimuli normally associated with food delivery (pulsing tone and light and the sound of the feeder when it was activated) were still present, but food was not delivered to the food tray in the chamber. With this procedure we tested the effects of saline, $3 \mathrm{mg} / \mathrm{kg}$ of THC, and $5.6 \mathrm{mg} / \mathrm{kg}$ of morphine, which were the peak doses under conditions of normal food delivery. As a positive control, we studied the effects of the psychostimulant methamphetamine at a dose of $1 \mathrm{mg} / \mathrm{kg}$ that we extensively used as training dose of methamphetamine in drug discrimination studies (eg Munzar et al, 2004).

\section{Drugs}

THC $(50 \mathrm{mg} / \mathrm{ml}$ in ethanol from the National Institute on Drug Abuse, Rockville, MD) was dissolved in a solution of $40 \%(\mathrm{w} / \mathrm{v})$ of cyclodextrin (RBI/SIGMA, Natick, MA). Morphine $\mathrm{HCl}$, methamphetamine (National Institute on Drug Abuse), and naloxone $\mathrm{HCl}$ (RBI/Sigma) were dissolved in saline. Rimonabant (SR-141716; National Institute on Drug Abuse) was suspended in $0.3 \%$ Tween- 80 in saline and administered intrapeitoneally (i.p.) in a volume of $2 \mathrm{ml} / \mathrm{kg}$. THC and morphine were given 30 min before the start of the session, methamphetamine and saline were given $15 \mathrm{~min}$ before the start of the session, rimonabant was given $60 \mathrm{~min}$ before the start of the session, and naloxone was given $45 \mathrm{~min}$ before the start of the session.

\section{Data Analysis}

Food reinforcement data were analyzed as the response requirement of the last ratio completed per session (means \pm SEM) after a logarithmic transformation. Data were subjected to repeated-measures ANOVA, followed when appropriate by a post hoc Dunnet's test, with comparisons to baseline conditions for effects of single treatments and with comparisons to the $3 \mathrm{mg} / \mathrm{kg}$ THC or $5.6 \mathrm{mg} / \mathrm{kg}$ morphine tests for effects of combinations. Food reinforcement data for the effects of morphine, THC, and methamphetamine for the no food-delivery condition were subjected to a repeated-measures two-way ANOVA, followed by a post hoc Student-Newmann-Keuls' test.

Selected sets of data were also analyzed as number of pellets (means \pm SEM) and amount of food (means \pm SEM) consumed per session. A Student $t$-test of selected comparisons was performed to assess significant statistical differences. Changes were considered significant when $p<0.05$.

\section{RESULTS}

\section{Effects of Free Feeding and Food Deprivation on Food-Reinforced Behavior Under a Progressive-Ratio Schedule}

Under basal conditions, response rate, break point (Figure 1b), and number of food pellets consumed per session (Figure 1a) were stable throughout the experiment. In test sessions, break points were dependent on food motivation. When rats were completely nonfood deprived (free feeding for $24 \mathrm{~h}$ ), their weights significantly increased (Figure 2a) and their break points were lower than baseline conditions (Figure $2 b$ ) and, conversely, when rats were food deprived (no food for $24 \mathrm{~h}$ ), their weights significantly decreased compared to baseline conditions (Figure 2a) and their break points were higher compared to baseline conditions $(\mathrm{F}(2,22)=121.486, p<0.0001$ for changes in weight and $\mathrm{F}(2,22)=85.042, p<0.0001$ for changes in break points) (Figure $2 b$ ). The number of pellets and amount of food consumed in milligram during these test sessions are shown in Table 1.

\section{Effects of the Cannabinoid Agonist THC and the Opioid Agonist Morphine}

Both THC (Figure 3a) and morphine (Figure 3b) produced dose-dependent increases in the break point, as measured 

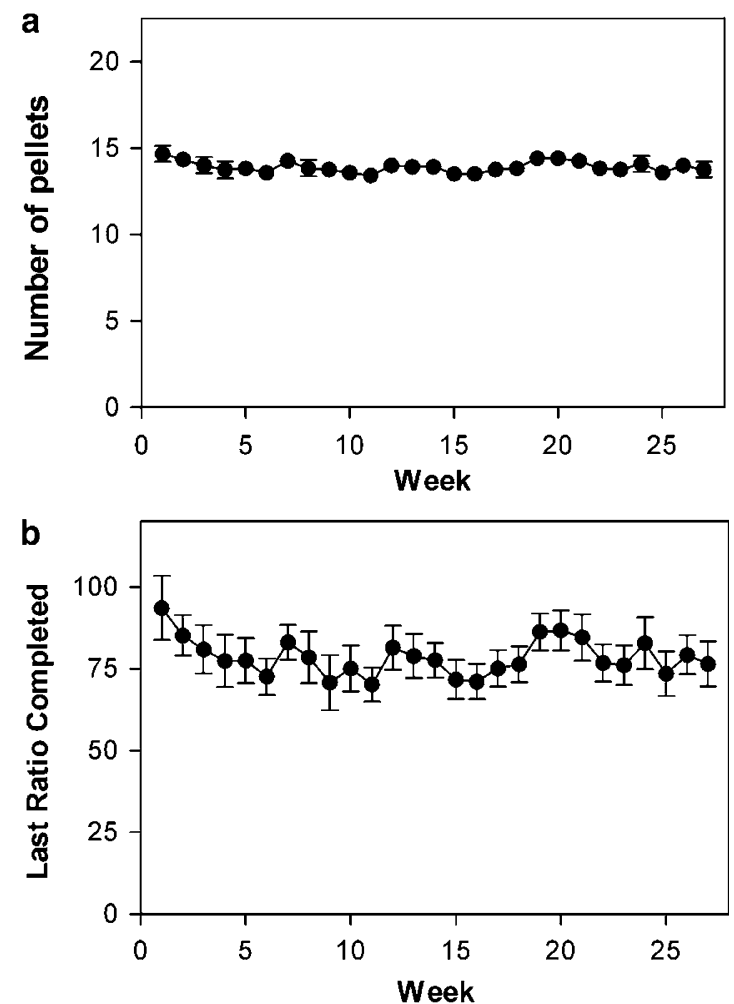

Figure I Weekly average baseline responding and food obtained and consumed over the entire study. Data are expressed as means ( \pm SEM) of (a) the number of pellets obtained per session or (b) as the last ratio completed (break point) as a function of experimental week. Note that data from test sessions is not included in this figure and data from baseline sessions when rats did not receive test injections of drugs is included whether or not stable baseline criteria were met $(n=12)$.

by the response requirement of the last ratio completed in the session $(\mathrm{F}(4,44)=3.489, \quad p<0.05$ for THC and $\mathrm{F}(4,44)=3.790, p<0.01$ for morphine). Peak effects for THC and morphine were found at doses of $3 \mathrm{mg} / \mathrm{kg}$ THC and $5.6 \mathrm{mg} / \mathrm{kg}$ morphine, respectively. The number of pellets and amount of food consumed in milligram during these two test sessions are shown in Table 1. The increases in break points found with both THC and morphine were likely due to increased motivation to respond for food and not to an increase in general activity, since these doses of THC and morphine have been reported to produce decreases, rather than increases, in spontaneous activity (Jarbe et al, 2002; Kalinichev et al, 2004) and did not increase break points in the no food-delivery condition (see below). Higher doses produced large increases in break points in some rats and complete disruption of responding in other rats, resulting in inverted U-shaped dose-response curves when data were averaged.

Cumulative records from one rat (E23) are shown in Figure 3. Note that administration of both THC (Figure 4b) and morphine (Figure 4e) dramatically increased both the break point and the duration of the experimental session compared to baseline conditions (Figure 4a).

\section{Effects of THC and Morphine Depend on Food Delivery}

In order to investigate whether THC- and morphineinduced increases in break points could be due to increases
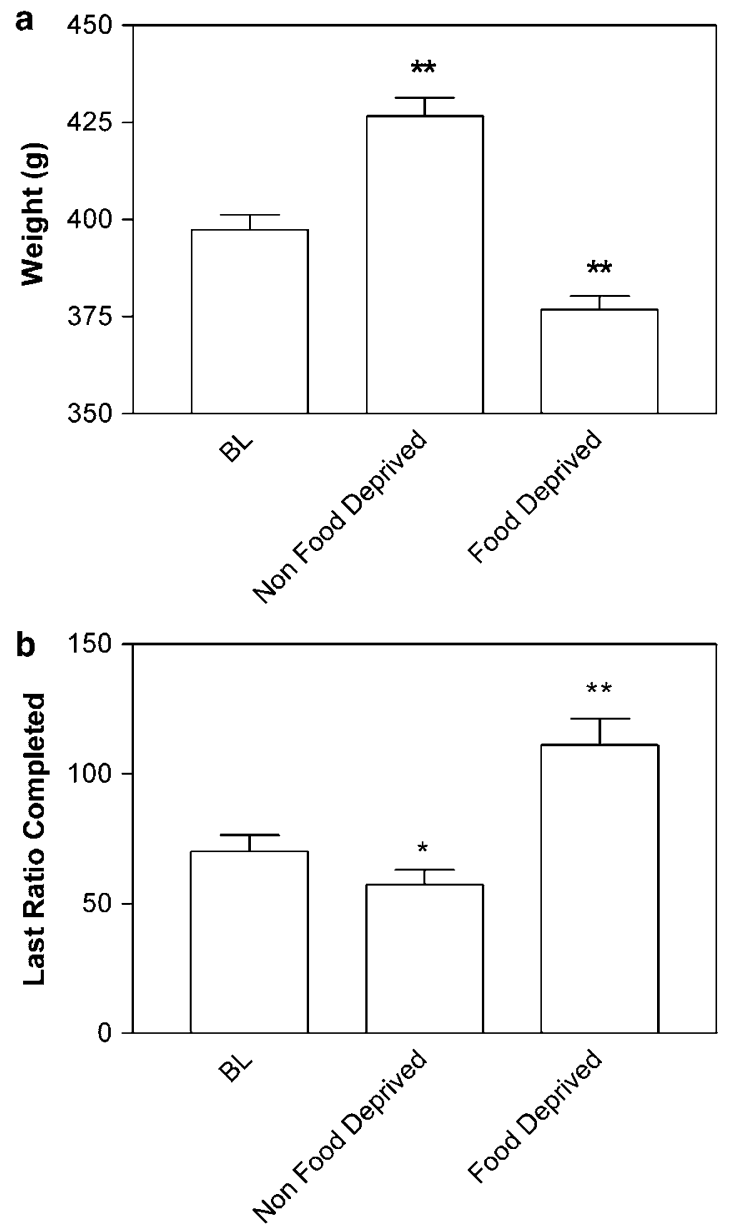

Figure 2 Effects of deprivation and free feeding on body weight and the motivation to respond for food. Data are expressed as means $( \pm S E M)$ of (a) grams of weight or (b) the last ratio completed (break point) under baseline (BL) conditions and during test conditions after $24 \mathrm{~h}$ of food deprivation or $24 \mathrm{~h}$ of free feeding. $* p<0.05$, $* * * 0.01$. Post hoc comparison of BL vs test sessions after significant ANOVA for repeated measures main effect, Dunnet's test $(n=12)$.

in general activity, we performed a series of experiments in which, during test sessions, the animal's responding was not reinforced. We found that responding by rats was dependent on actual reinforcement, that is, actual delivery and consumption of food pellets as demonstrated by the fact that preventing delivery of food to the food tray in the chamber dramatically reduced break points $(\mathrm{F}(7,77)=40.532, p<0.0001)$. THC $(3 \mathrm{mg} / \mathrm{kg})$ and morphine $(5.6 \mathrm{mg} / \mathrm{kg})$ increased break points only when they were administered before sessions in which operant responding by rats was reinforced by food delivery and consumption (left part of the Figure 5). In contrast, when operant responding was not reinforced, rats injected with THC or morphine did not nose-poke more than when they received saline injection and they responded significantly less than under basal conditions (right part of the Figure 5). In contrast, $1 \mathrm{mg} / \mathrm{kg}$ methamphetamine increased break points compared to basal levels both when responding by rats was reinforced and when it was not (Figure 5), although break points were higher when food delivery and consumption took place. 
Table I Number of Pellets Obtained and Food Consumption Per Session Under Baseline Conditions and after Treatment with the Different Doses of Cannabinoid and Opioid Compounds

\begin{tabular}{|c|c|c|}
\hline Treatment & $\begin{array}{c}\text { Number of } \\
\text { pellets }\end{array}$ & $\begin{array}{c}\text { Food consumption } \\
(\mathbf{m g})\end{array}$ \\
\hline Baseline level & $|3.8|( \pm 0.24)$ & $621.53( \pm 10.83)$ \\
\hline Nonfood deprived & $12.27( \pm 0.4 \mathrm{I})^{* * * * *}$ & $552.27( \pm \text { | 8.29) })^{* * * *}$ \\
\hline Food deprived & I5.54 ( $( \pm 0.39)^{* * * * *}$ & $699.54( \pm 17.55)^{* * * *}$ \\
\hline THC, $3 \mathrm{mg} / \mathrm{kg}$ & $18.25( \pm 1.09)^{* * * * *}$ & $821.25( \pm 48.96)^{* * * *}$ \\
\hline Morphine, $5.6 \mathrm{mg} / \mathrm{kg}$ & $16.33( \pm 1.20)^{* * *}$ & $735.00( \pm 54.08)^{* *}$ \\
\hline Rimonabant, I mg/kg & $13.00( \pm 0.58)^{*}$ & $585.00( \pm 25.99)^{*}$ \\
\hline Rimonabant, $3 \mathrm{mg} / \mathrm{kg}$ & $|2.4|( \pm 0.75)^{* * *}$ & $558.75( \pm 33.90)^{* * *}$ \\
\hline Naloxone, I mg/kg & $14.17( \pm 0.69)$ & $637.50( \pm 31.25)$ \\
\hline Naloxone, $3 \mathrm{mg} / \mathrm{kg}$ & $|0.9|( \pm 1.17)^{* * *}$ & $491.25( \pm 52.68)^{* * *}$ \\
\hline Rimonabant 3+THC 3 & $11.67( \pm 1.66)^{\# \# \#}$ & $525.00( \pm 74.79)^{\# \# \#}$ \\
\hline Naloxone I+morphine 5.6 & $\mid 4.08( \pm 0.61)^{\$ \$ \$}$ & $633.75( \pm 27.39)^{\$ \$ \$}$ \\
\hline Rimonabant 3+morphine 5.6 & $12.67( \pm 1.11)^{\$ \$}$ & $570.00(49.95)^{\$ \$}$ \\
\hline Naloxone 3+THC 3 & $6.91( \pm 1.79)^{\# \#}$ & $311.63( \pm 74.82)^{\# \#}$ \\
\hline
\end{tabular}

Data are mean \pm SEM of the number of pellets obtained and milligram of food per session, $* * *<0.01$, **** $<0.001$.

$* p<0.05$ compared to basal level condition.

${ }^{\#} p<0.05$, \#\# $p<0.0$ I, \#\#\# $p<0.00$ I compared to THC $3 \mathrm{mg} / \mathrm{kg}$ alone treatment.

$\$_{p}<0.05,{ }^{\$} \$_{p}<0.01,{ }^{\$} \$ p<0.001$ compared to morphine $5.6 \mathrm{mg} / \mathrm{kg}$ alone treatment using a Student's $t$-test.
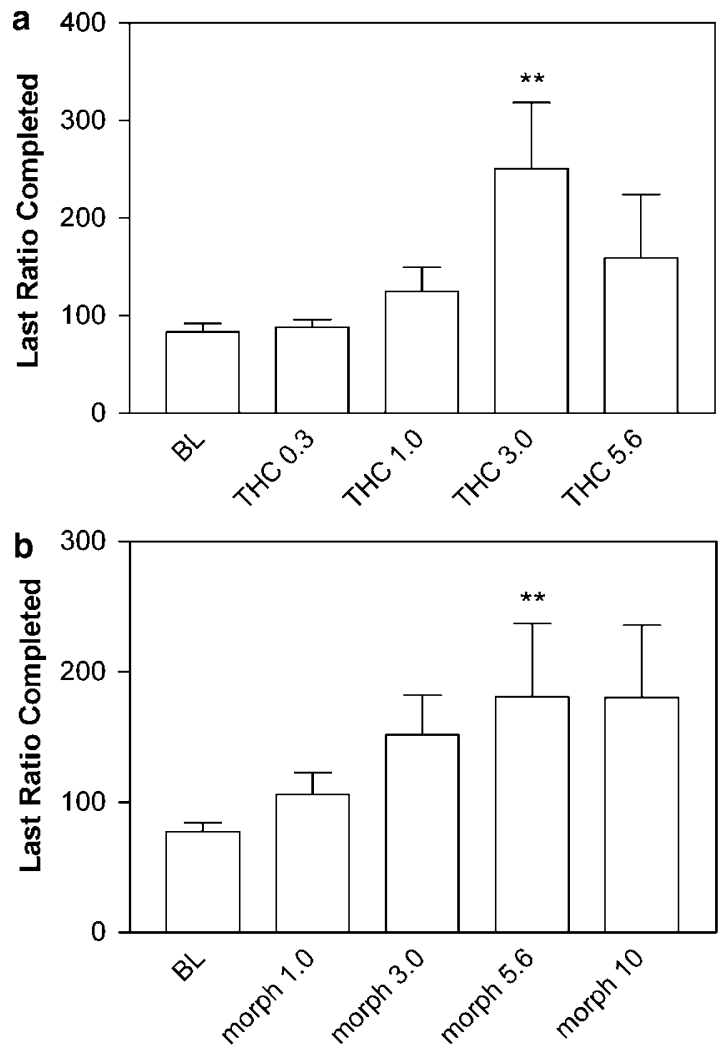

Figure 3 Effects of THC and morphine on the motivation to respond for food. Data are expressed as means ( + SEM) of the last ratio completed (break point) under baseline (BL) conditions and after administration of (a) THC $(0.3-5.6 \mathrm{mg} / \mathrm{kg}$ i.p.) and (b) morphine $(1-10 \mathrm{mg} / \mathrm{kg}$ i.p.). Both THC and morphine were administered $30 \mathrm{~min}$ before the session. ${ }^{*} p<0.05$, *** $p<0.01$. Post hoc comparison of BL vs treatment sessions after significant ANOVA for repeated measures main effect, Dunnet's test $(n=12)$.

\section{Effects of the Cannabinoid CB1 Antagonist Rimonabant and the Opioid Antagonist Naloxone}

Both rimonabant (Figure 6a) and naloxone (Figure 6b) produced a dose-dependent decrease in the break point as measured by the last ratio completed $(\mathrm{F}(3,33)=8.933$; $p<0.001$ for rimonabant and $\mathrm{F}(3,33)=5.804, p<0.01$ for naloxone) (Figure 6). The number of pellets and amount of food consumed in milligram during these test sessions are shown in Table 1. The decreases in break points were found with both rimonabant and naloxone at the $3 \mathrm{mg} / \mathrm{kg}$ dose and were probably due to a decreased motivation to respond for food and not to a nonspecific impairment of operant responding, since these doses of rimonabant and naloxone do not reduce spontaneous activity (Holtzman and Jewett, 1973; Freedland et al, 2000; Jarbe et al, 2002).

\section{Dose-Dependent Blockade of THC's Effects by Rimonabant and of Morphine's Effects by Naloxone}

The increase in break point produced by the $3 \mathrm{mg} / \mathrm{kg}$ dose of THC was significantly and dose dependently blocked by administration of rimonabant $(\mathrm{F}(3,33)=8.823, p<0.01)$ (Figure 7a). Also, the increase in break point produced by the $5.6 \mathrm{mg} / \mathrm{kg}$ dose of morphine was dose dependently blocked by administration of naloxone $(\mathrm{F}(3,33)=4.467$, $p<0.01$ ) (Figure $7 \mathrm{~b}$ ). The number of pellets and amount of food consumed in milligram during these test sessions are shown in Table 1. These results indicate that the effects of THC were mediated by cannabinoid CB1 receptors and the effects of morphine were mediated by mu-opioid receptors. This is further illustrated by the representative cumulative records in Figure 4 showing that $1 \mathrm{mg} / \mathrm{kg}$ of rimonabant completely antagonized the effects of $3 \mathrm{mg} / \mathrm{kg}$ THC (Figure $4 \mathrm{c}$ ), and $1 \mathrm{mg} / \mathrm{kg}$ of naloxone completely antagonized the effects of $5.6 \mathrm{mg} / \mathrm{kg}$ morphine (Figure $4 \mathrm{f}$ ) on responding under the progressive-ratio schedule.

\section{Dose-Dependent Reduction of THC's Effects by Naloxone and of Morphine's Effects by Rimonabant}

Rimonabant completely reversed the increase in break points produced by morphine $(\mathrm{F}(3,33)=8.826, p<0.01)$ and, conversely, naloxone completely reversed the increases in break points produced by THC $(\mathrm{F}(3,33)=8.287, p<0.01)$ (Figure 8). The number of pellets and amount of food consumed in milligram during these test sessions are shown in Table 1. Again, the effects are illustrated by representative cumulative records in Figure 4 showing that $1 \mathrm{mg} / \mathrm{kg}$ of rimonabant markedly reduced the effects of $5.6 \mathrm{mg} / \mathrm{kg}$ morphine (Figure $4 \mathrm{c}$ ), and $1 \mathrm{mg} / \mathrm{kg}$ of naloxone markedly reduced the effects of $3 \mathrm{mg} / \mathrm{kg}$ THC (Figure $4 \mathrm{f}$ ) on responding under the progressive-ratio schedule.

\section{DISCUSSION}

The present findings indicate that endogenous opioid and cannabinoid systems are markedly and interdependently involved in modulating motivational aspects of food reinforcement revealed under a progressive-ratio schedule. Both the cannabinoid $\mathrm{CB} 1$ receptor agonist THC and the mu-opioid receptor agonist morphine significantly 

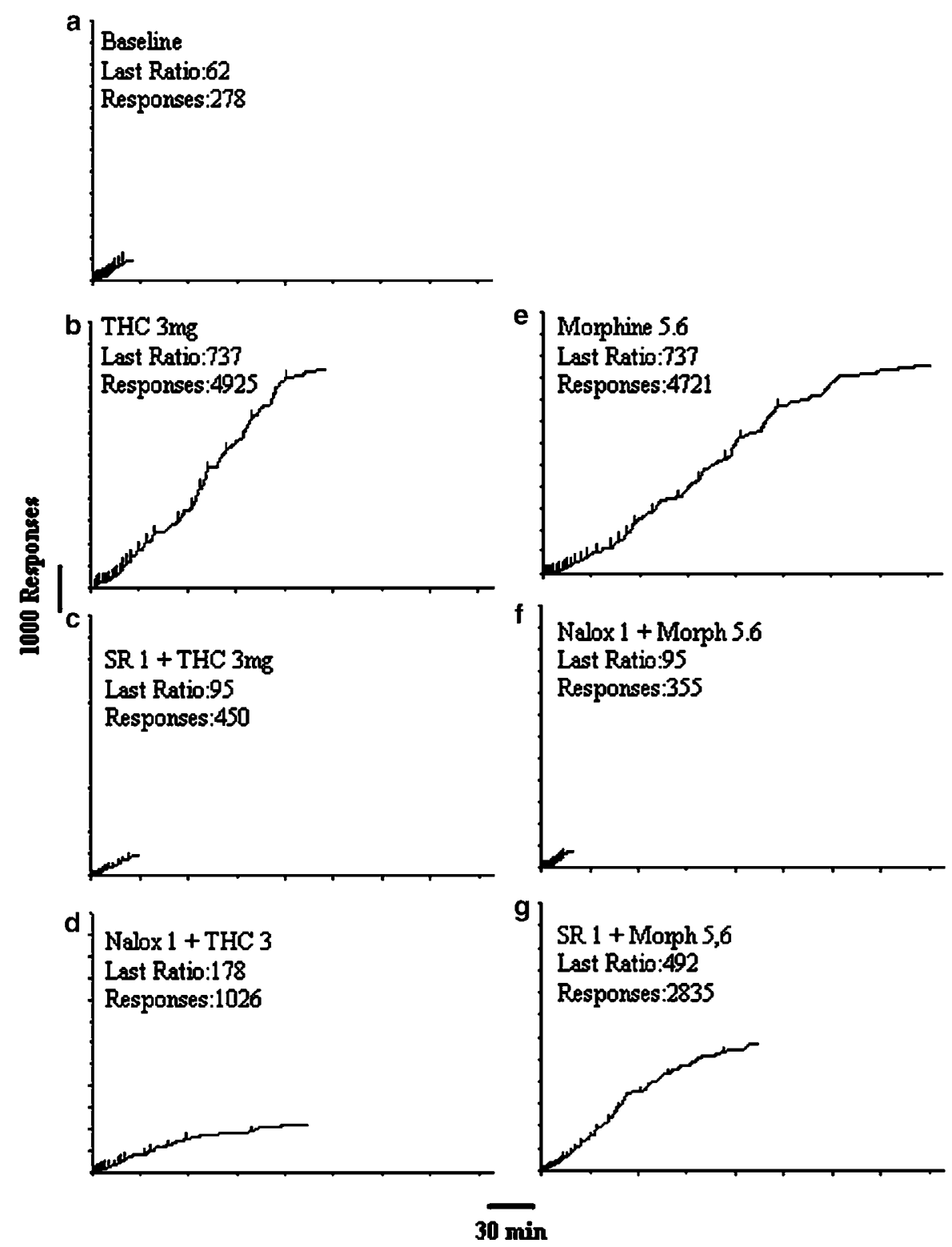

Figure 4 Cumulative-response records of food-reinforced responding under the progressive-ratio schedule. Representative cumulative-response records from one rat (E23). Ordinates represent cumulative number of nose-poke responses and abscissae represent time. Short vertical strokes on the cumulative record indicate food delivery. Note that THC and morphine produced dramatic increases in both break point and length of the session. Also note that rimonabant completely blocked the effects of THC and naloxone completely blocked the effects of morphine. Finally, rimonabant dramatically reduced the effects of morphine and naloxone dramatically reduced the effects of THC.

increased the motivation to respond for food, while the cannabinoid CB1 receptor antagonist rimonabant and the preferential mu-opioid receptor antagonist naloxone significantly reduced the motivation to respond for food, as measured by break point values. In a previous study (Solinas et al, 2003), we did not find significant effects on break points for food under a progressive-ratio schedule when $1 \mathrm{mg} / \mathrm{kg}$ of rimonabant was given for 3 consecutive days. However, there was a decrease in break point on the first day of treatment in that study similar in magnitude to that in the present study (12\% decrease $v s 13 \%$ decrease in the present study) and the smaller number of animals used in that study ( $n=6 v s n=12$ in the present study) may have prevented demonstration of a significant effect. The orexigenic (increased appetite) effects of THC appeared to be mediated by cannabinoid CB1 receptors, while those of morphine appeared to be mediated by opioid receptors, since they were completely and dose dependently blocked by rimonabant and naloxone, respectively. Even more striking, however, was the finding that the effects of THC in increasing break points under the progressive-ratio schedule appeared to be almost completely dependent on secondary activation of endogenous opioid systems, since naloxone completely reversed the effects of THC on foodreinforced behavior. Similarly, the effects of morphine in increasing break points under the progressive-ratio schedule appeared to be almost completely dependent on activation of endogenous cannabinoid systems, since rimonabant completely reversed the effects of morphine on food-reinforced behavior. Thus, cannabinoids and 


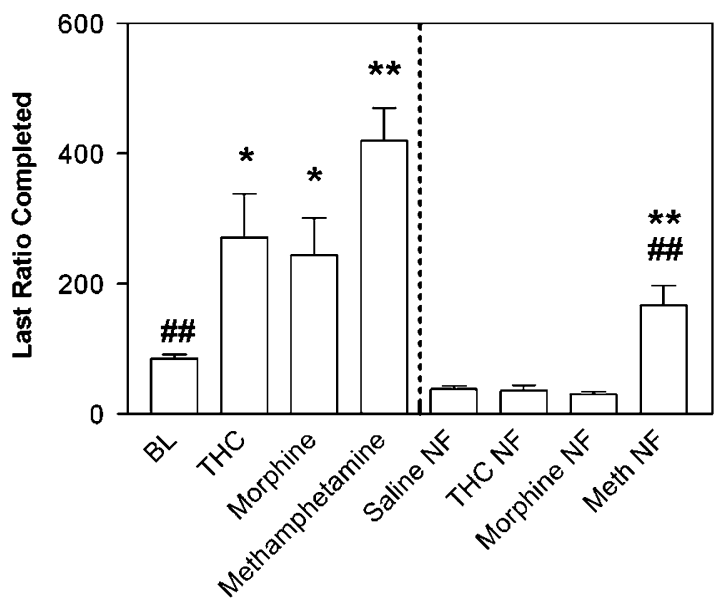

Figure 5 Effects of THC, morphine, and methamphetamine on motivation to respond for food with and without delivery of food pellets. Data are expressed as means ( \pm SEM) of the last ratio completed (break point) under baseline (BL) (left part of graph) or saline-control conditions (right part of graph), and after administration of $3 \mathrm{mg} / \mathrm{kg}$ of THC, $5.6 \mathrm{mg} / \mathrm{kg}$ of morphine, and I mg/kg of methamphetamine in normal food-delivery condition of (left part of graph) and in the no food-delivery (NF) condition (right part of graph). THC and morphine were administered $30 \mathrm{~min}$ before the session and methamphetamine and saline were administered $15 \mathrm{~min}$ before the session. $* p<0.05$, $* *<<0.01$ compared to baseline conditions; $\# \#<<0.0$ I compared to saline treatment with no food (NF) delivery. Post hoc comparisons after significant two-way ANOVA for repeated measures main effect, Student-Newmann-Keuls' test $(n=12)$

opioids appear to produce their effects on the effort that is expended to obtain food under progressive-ratio schedules by simultaneously activating endogenous cannabinoid and opioid systems, with synergistic results. These results support the suggested therapeutic utility of cannabinoid $\mathrm{CB} 1$ receptor agonists for the treatment of anorexic states and cannabinoid CB1 receptor antagonists such as rimonabant for the treatment of obesity (Cota et al, 2003; Harrold and Williams, 2003).

Cannabinoid and opioid systems appear to be intimately involved in the regulation of food intake. The ability of cannabis to increase appetite and food intake in humans has been known for centuries (Abel, 1975) and some animal studies have demonstrated a significant role for the endocannabinoid system in the regulation of feeding behavior. For example, both THC and the endogenous cannabinoid $\mathrm{CB} 1$ receptor ligand anandamide increase the intake of food in rats (Williams et al, 1998; Williams and Kirkham, 1999; Hao et al, 2000; Jamshidi and Taylor, 2001; Williams and Kirkham, 2002a) and increase the consumption of sweet solutions (Gallate et al, 1999). Conversely, the cannabinoid $\mathrm{CB} 1$ receptor antagonists rimonabant and AM251 decrease the intake of food and the consumption of sweet solutions (Arnone et al, 1997; Colombo et al, 1998; Simiand et al, 1998; Freedland et al, 2000; McLaughlin et al, 2003; Thornton-Jones et al, 2004). Consistent with these findings, when we looked at the number of pellets and amount of food consumed per session in the present study, we found a significant increase after THC administration and a significant decrease after rimonabant administration. In addition, high levels of endocannabinoids are present in brain areas involved in the regulation of food intake such the hypothalamus (Gonzalez et al, 1999; Howlett, 2002) and
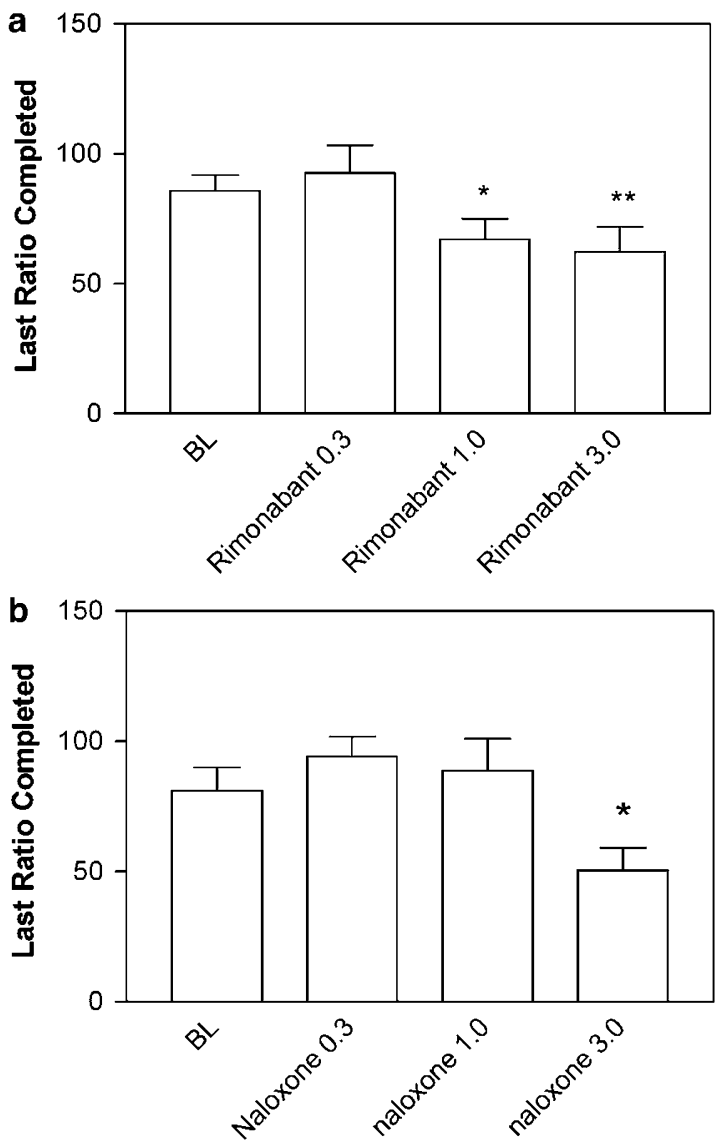

Figure 6 Effects of rimonabant and naloxone on the motivation to respond for food. Data are expressed as means $( \pm S E M)$ of the last ratio completed (break point) under baseline (BL) conditions and after administration of (a) rimonabant $(0.3-3 \mathrm{mg} / \mathrm{kg}$ i.p.) and (b) naloxone (0.3-3 mg/kg i.p.). Rimonabant and naloxone were administered 60 and $45 \mathrm{~min}$ before the session, respectively. ${ }^{*} p<0.05$, ${ }^{*} * 0<0.01$. Post hoc comparisons of $\mathrm{BL}$ vs treatment sessions after significant ANOVA for repeated measures main effect, Dunnet's test $(n=12)$.

the levels of endocannabinoids are under the control of leptin, a main hormone responsible for negative regulation of food intake (Di Marzo et al, 2001).

Similarly to cannabinoids, opioids can alter the regulation of food intake. For example, morphine increases the intake of sweet solutions, whereas opioid antagonists reduce food intake (Cooper and Kirkham, 1990; Gosnell and Levine, 1996). In the present study, when we looked at the number of pellets and amount of food consumed per session, we consistently found a significant increase after morphine administration and a significant decrease after naloxone administration. Also, high levels of opioid peptides are present in brain areas involved in the regulation food intake (Mansour et al, 1987) and their synthesis and release appear to play important roles in food-intake homeostasis (Nencini and Graziani, 1990; Low et al, 2003). The effects of both cannabinoids and opioids on regulation of food intake may be due, at least in part, to the ability of THC and morphine to increase hedonic 'incentive' values of food such as palatabilty (Kelley et al, 2002; Higgs et al, 2003), and this might become most evident under conditions where the organism must expend effort to obtain food, rather than simply having food freely available (Williams et al, 1998; 

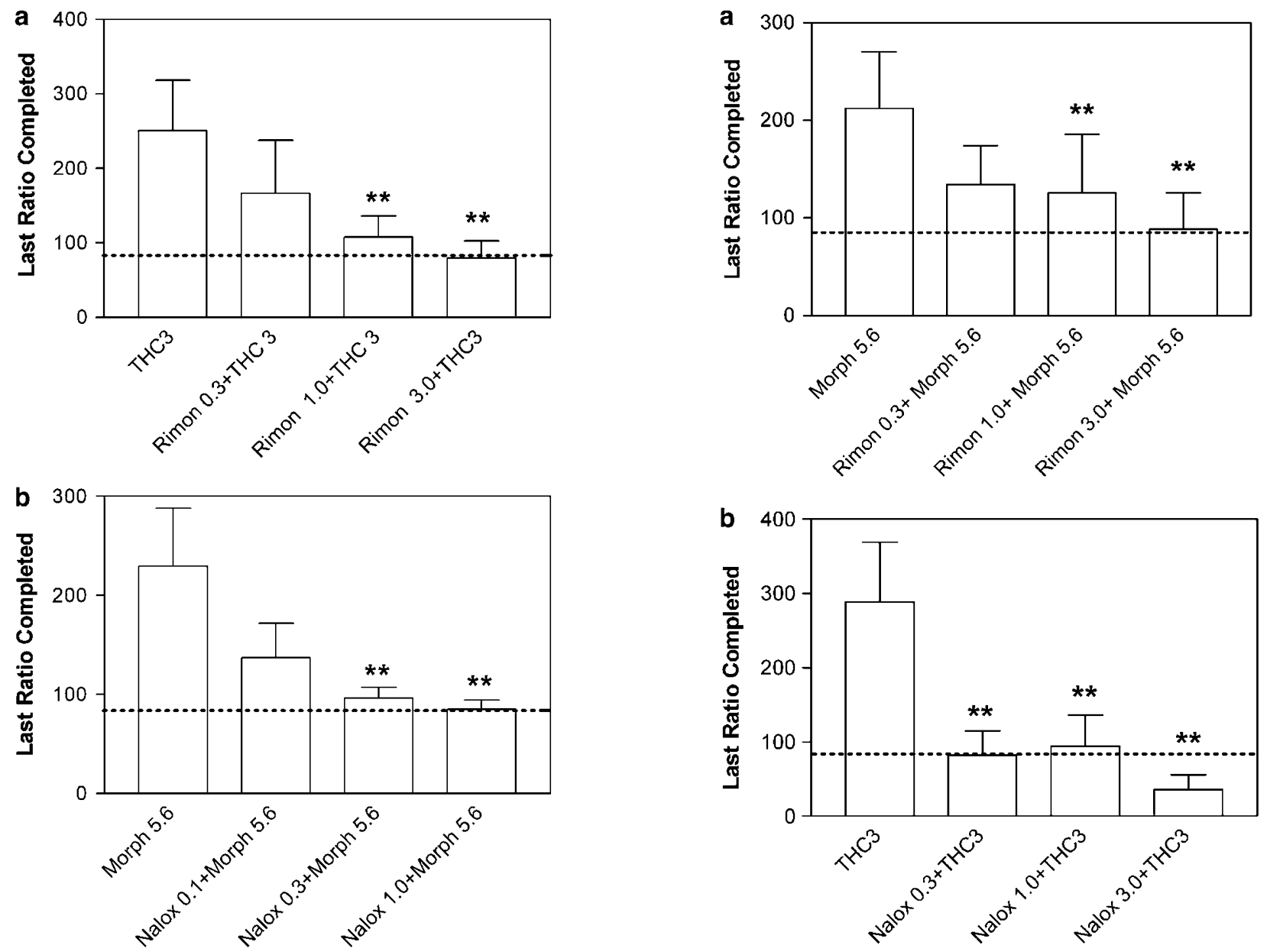

Figure 7 Effects of rimonabant (Rimon) on THC's effects and of naloxone (Nalox) on morphine's effects on the motivation to respond for food. Data are expressed as means $( \pm$ SEM) of the last ratio completed (break point) after administration of (a) THC $3 \mathrm{mg} / \mathrm{kg}$ i.p alone or in combination with different doses of rimonabant $(0.3-3 \mathrm{mg} / \mathrm{kg}$ i.p.) and (b) morphine $5.6 \mathrm{mg} / \mathrm{kg}$ i.p. alone or in combination of different doses of naloxone $(0.1-1 \mathrm{mg} / \mathrm{kg}$ i.p.). The dotted line indicates the break points under baseline conditions. ${ }^{*} p<0.05$, $* * * 0.01$. Post hoc comparisons of $\mathrm{THC}$ vs THC + rimonabant test sessions and morphine vs morphine + naloxone test sessions after significant ANOVA for repeated measures main effect, Dunnet's test $(n=12)$.

Williams and Kirkham, 1999; Hao et al, 2000; Jamshidi and Taylor, 2001; Williams and Kirkham, 2002a, b). Such a motivational aspect of food reinforcement can be studied by measuring the amount of effort an organism will expend to obtain food pellets for consumption under operant progressive-ratio schedules of food reinforcement (Hodos, 1961).

Several lines of research have demonstrated the existence of strong interactions between endogenous cannabinoid and opioid systems (Manzanares et al, 1999; Tanda and Goldberg, 2003) and recently similar interactions have been described in the regulation of feeding (Rowland et al, 2001; Williams and Kirkham, 2002b). Initially, the ability of selective mu-opioid receptor antagonists to block the effects of THC on dopamine release in the nucleus accumbens was described, suggesting that the rewarding effects of THC were dopaminergically mediated and involved the activation of endogenous opioid systems (Chen et al, 1990; Tanda

Figure 8 Effects of rimonabant (Rimon) on morphine's effects and of naloxone (Nalox) on THC's effects on the motivation to respond for food. Data are expressed as means ( + SEM) of the last ratio completed (break point) after administration of (a) morphine $5.6 \mathrm{mg} / \mathrm{kg}$ i.p alone or in combination with different doses of rimonabant $(0.3-3 \mathrm{mg} / \mathrm{kg}$ i.p.) and (b) THC $3 \mathrm{mg} / \mathrm{kg}$ i.p. alone or in combination of different doses of naloxone $(0.1-1 \mathrm{mg} / \mathrm{kg}$ i.p.). The dotted line indicates the break points under baseline condition. $* p<0.05$, $* * p<0.01$. Post hoc comparison of morphine vs morphine + rimonabant test sessions and of THC vs THC + naloxone test sessions after significant ANOVA for repeated measures main effect, Dunnet's test $(n=12)$.

et al, 1997). These findings have been confirmed and extended (Tanda and Goldberg, 2003; Justinova et al, 2004; Spano et al, 2004). There have also been direct demonstrations of THC-induced release of endogenous opioids in brain areas involved in motivation (Valverde et al, 2001; Solinas et al, 2004). Thus, blocking opioid receptors would block the effects of these released opioids.

After the cloning of the cannabinoid CB1 receptor (Matsuda et al, 1990), it was shown that pharmacological blockade or genetic ablation ('knockout' mice) of cannabinoid CB1 receptors decreases many of the effects of opioids (Ledent et al, 1999; Mascia et al, 1999; Martin et al, 2000; Cossu et al, 2001; De Vries et al, 2001; Solinas et al, 2003). Brain levels of endogenous cannabinoids have been reported to be increased, decreased or unchanged after the administration of opioids depending on which endocannabinoid was measured (anandamide or 2-AG) and 
depending on the protocol of opioid administration (acute or chronic) (Gonzalez et al, 2003; Vigano et al, 2003, 2004). It is believed that anandamide and 2-AG have different roles in brain functioning. Anandamide appears to be involved in neurotransmission, whereas 2-AG appears to have mostly housekeeping functions (Piomelli, 2003); thus, modulation of opioid effects is most likely mediated by changes in anandamide rather than 2-AG levels. Also, the conditions of testing in our study most likely resemble those of an acute injection rather those of a chronic treatment; thus, the effects of an acute administration of opioid agonists appear to be more relevant for our study. It has been recently shown that acute administration of morphine increases the levels of anandamide (but not $2-A G)$ in brain areas such as the nucleus accumbens, the caudate putamen, and the hippocampus (Vigano et al, 2004). Thus, release of anandamide may play a role in the effects of systemically injected opioids and blocking cannabinoid receptors would block the effects of this released anandamide.

Cannabinoid and opioid receptors, especially mu-opioid receptors, show similar brain distributions and have been shown to have at least a partial degree of colocalization in brain areas involved in motivated behaviors and in homeostatic regulation of food intake (Mansour et al, 1987; Herkenham et al, 1991; Rodriguez et al, 2001) and they share similar second-messenger cascades (Reisine et al, 1996; Howlett, 2002). These facts suggest that cannabinoid and opioid receptors could interact at the level of the cell membrane (direct protein-protein heterodimerization) or at the level of signaling pathways. In support of this mechanism, it has been demonstrated that in mu-opioid receptor-deficient 'knockout' mice, the signaling strength of cannabinoid CB1 receptor agonists is significantly reduced (Berrendero et al, 2003). These mechanisms, a release of endogenous compounds and a potentiation of the cellular consequences of receptor activation, are not mutually exclusive and it is probable that both levels of interactions take place and participate in behavioral responses.

The effects of both opioid and cannabinoid agonists were completely dependent on actual food reinforcement, as demonstrated by the fact that THC and morphine did not increase responding and break points when food was not delivered to the food tray in the experimental chamber. In contrast, methamphetamine increased both responding and break points even when food was not delivered. The effects of methamphetamine when food was not delivered could be attributed to either (1) a nonspecific enhancement of motor activity, (2) an enhancement of the conditioned-reinforcing effects of the food-paired exteroceptive stimuli (see (Robbins et al, 1983), or (3) an increase in 'hunger' comparable to increasing the level of food deprivation, although this would be unlikely because methamphetamine is generally an appetite suppressant. In contrast, THC and morphine did not increase responding and break points at all when food was not delivered. Therefore, it is clear that the enhancing effects of THC and morphine on responding for food when food delivery was maintained are not due to nonspecific increases in motor activity, conditioned reinforcement, or hunger. Instead, the effects of THC and morphine on responding for food when food delivery was maintained are consistent with an enhancement of the palatability of food (Kelley et al, 2002; Higgs et al, 2003; Cooper, 2004).

The cannabinoid and opioid manipulations in this study had tangible and clearcut effects on an important aspect of food-motivated behavior, that is, the amount of effort the animal would expend to obtain food. We have interpreted changes in break points under our progressive-ratio procedure as reflecting changes in the motivational value of food to the animal. However, in making this interpretation, it should be noted that break points under a progressive-ratio schedule could conceivably be influenced by nonmotivational factors such as perseveration of responding, changes in activity levels, or enhancements in motor performance. It might be possible to further dissect behavior under progressive-ratio schedules and exclude such interferences. For example, changing the physical effort rats have to expend to obtain food pellets by increasing the height of a lever or the force necessary to activate the lever could help dissect possible effects of the drugs on motor performance (see Schmelzeis and Mittleman, 1996; Salamone et al, 2003). Such an extended behavioral analysis deserves future investigation.

In conclusion, our results clearly demonstrate the existence of strong interactions between endogenous cannabinoid and opioid systems at the level of motivational responses for food reinforcement. The activation of opioid and cannabinoid systems seem to be different but converging synergistic mechanisms that have important modulatory roles in the physiological and pathophysiological motivation for food reinforcement in animals and probably in humans. In addition, the ability of cannabinoid compounds to bidirectionally regulate the maximal effort expended for food reinforcement provides further support the proposed therapeutic utility of cannabinoid CB1 receptor agonists in the treatment of severely reduced food consumption (eg wasting syndromes associated with chemotherapy and HIV) and cannabinoid CB1 receptor antagonists in the treatment of excessive food consumption (eg obesity).

\section{ACKNOWLEDGEMENTS}

The research performed was supported by the Intramural Research Program of the National Institute on Drug Abuse, National Institutes of Health, and Department of Health and Human Services. We would like to thank Leigh Panlilio for comments on an earlier version of this paper.

\section{REFERENCES}

Abel EL (1975). Cannabis: effects on hunger and thirst. Behav Biol 15: 255-281.

Arnold JM, Roberts DC (1997). A critique of fixed and progressive ratio schedules used to examine the neural substrates of drug reinforcement. Pharmacol Biochem Behav 57: 441-447.

Arnone M, Maruani J, Chaperon F, Thiebot MH, Poncelet M, Soubrie P et al (1997). Selective inhibition of sucrose and ethanol intake by SR 141716, an antagonist of central cannabinoid (CB1) receptors. Psychopharmacology (Berl) 132: 104-106.

Berrendero F, Mendizabal V, Murtra P, Kieffer BL, Maldonado R (2003). Cannabinoid receptor and WIN 55 212-2-stimulated $\left[{ }^{35} \mathrm{~S}\right]$-GTPgammaS binding in the brain of mu-, delta- and 
kappa-opioid receptor knockout mice. Eur J Neurosci 18: 2197-2202.

Berry EM, Mechoulam R (2002). Tetrahydrocannabinol and endocannabinoids in feeding and appetite. Pharmacol Ther 95: 185-190.

Chen JP, Paredes W, Li J, Smith D, Lowinson J, Gardner EL (1990). Delta 9-tetrahydrocannabinol produces naloxone-blockable enhancement of presynaptic basal dopamine efflux in nucleus accumbens of conscious, freely-moving rats as measured by intracerebral microdialysis. Psychopharmacology (Berl) 102: 156-162.

Colombo G, Agabio R, Diaz G, Lobina C, Reali R, Gessa GL (1998). Appetite suppression and weight loss after the cannabinoid antagonist SR 141716. Life Sci 63: PL113-117.

Cooper SJ (2004). Endocannabinoids and food consumption: comparisons with benzodiazepine and opioid palatabilitydependent appetite. Eur J Pharmacol 500: 37-49.

Cooper SJ, Kirkham TC (1990). Basic mechanisms of opioids' effects on eating and drinking. In: Reid LD (ed). Opioids, Bulimia and Alcohol Abuse and Alcoholism. Springer: New York. pp 91-110.

Cossu G, Ledent C, Fattore L, Imperato A, Bohme GA, Parmentier $\mathrm{M}$ et al (2001). Cannabinoid CB1 receptor knockout mice fail to self-administer morphine but not other drugs of abuse. Behav Brain Res 118: 61-65.

Cota D, Marsicano G, Lutz B, Vicennati V, Stalla GK, Pasquali R et al (2003). Endogenous cannabinoid system as a modulator of food intake. Int J Obes Relat Metab Disord 27: 289-301.

Croxford JL (2003). Therapeutic potential of cannabinoids in CNS disease. CNS Drugs 17: 179-202.

De Vries TJ, Shaham Y, Homberg JR, Crombag H, Schuurman K, Dieben J et al (2001). A cannabinoid mechanism in relapse to cocaine seeking. Nat Med 7: 1151-1154.

Di Marzo V, Goparaju SK, Wang L, Liu J, Batkai S, Jarai Z et al (2001). Leptin-regulated endocannabinoids are involved in maintaining food intake. Nature 410: 822-825.

Fernandez JR, Allison DB (2004). Rimonabant Sanofi-Synthelabo. Curr Opin Invest Drugs 5: 430-435.

Freedland CS, Poston JS, Porrino LJ (2000). Effects of SR141716A, a central cannabinoid receptor antagonist, on food-maintained responding. Pharmacol Biochem Behav 67: 265-270.

Gallate JE, Saharov T, Mallet PE, McGregor IS (1999). Increased motivation for beer in rats following administration of a cannabinoid CB1 receptor agonist. Eur J Pharmacol 370: 233-240.

Gonzalez S, Manzanares J, Berrendero F, Wenger T, Corchero J, Bisogno T et al (1999). Identification of endocannabinoids and cannabinoid $\mathrm{CB}(1)$ receptor $\mathrm{mRNA}$ in the pituitary gland. Neuroendocrinology 70: 137-145.

Gonzalez S, Schmid PC, Fernandez-Ruiz J, Krebsbach R, Schmid HH, Ramos JA (2003). Region-dependent changes in endocannabinoid transmission in the brain of morphine-dependent rats. Addict Biol 8: 159-166.

Gosnell B, Levine AS (1996). Stimulation of ingestive behaviour by preferential and selective opioid agonists. In: Cooper SJ and Clifton PG (eds). Drug Receptor Subtypes and Ingestive Behaviour. Academic Press: San Diego. pp 147-166.

Griffiths RR, Findley JD, Brady JV, Dolan-Gutcher K, Robinson WW (1975). Comparison of progressive-ratio performance maintained by cocaine, methylphenidate and secobarbital. Psychopharmacologia 43: 81-83.

Hao S, Avraham Y, Mechoulam R, Berry EM (2000). Low dose anandamide affects food intake, cognitive function, neurotransmitter and corticosterone levels in diet-restricted mice. Eur J Pharmacol 392: 147-156.

Harrold JA, Williams G (2003). The cannabinoid system: a role in both the homeostatic and hedonic control of eating? Br J Nutr 90 729-734.
Herkenham M, Lynn AB, Johnson MR, Melvin LS, de Costa BR, Rice KC (1991). Characterization and localization of cannabinoid receptors in rat brain: a quantitative in vitro autoradiographic study. J Neurosci 11: 563-583.

Higgs S, Williams CM, Kirkham TC (2003). Cannabinoid influences on palatability: microstructural analysis of sucrose drinking after delta(9)-tetrahydrocannabinol, anandamide, 2arachidonoyl glycerol and SR141716. Psychopharmacology (Berl) 165: 370-377.

Hodos W (1961). Progressive ratio as a measure of reward strength. Science 134: 943-944.

Holtzman SG, Jewett RE (1973). Stimulation of behavior in the rat by cyclazocine: effects of naloxone. J Pharmacol Exp Ther 187: 380-390.

Howlett AC (2002). The cannabinoid receptors. Prostaglandins Other Lipid Mediat 68-69: 619-631.

Jamshidi N, Taylor DA (2001). Anandamide administration into the ventromedial hypothalamus stimulates appetite in rats. $\mathrm{Br} J$ Pharmacol 134: 1151-1154.

Jarbe TU, Andrzejewski ME, DiPatrizio NV (2002). Interactions between the CB1 receptor agonist delta 9-THC and the CB1 receptor antagonist SR-141716 in rats: open-field revisited. Pharmacol Biochem Behav 73: 911-919.

Justinova Z, Tanda G, Munzar P, Goldberg SR (2004). The opioid antagonist naltrexone reduces the reinforcing effects of delta 9 tetrahydrocannabinol (THC) in squirrel monkeys. Psychopharmacology (Berl) 173: 186-194.

Kalinichev M, White DA, Holtzman SG (2004). Individual differences in locomotor reactivity to a novel environment and sensitivity to opioid drugs in the rat. I. Expression of morphineinduced locomotor sensitization. Psychopharmacology (Berl) 177: 61-67.

Kelley AE, Bakshi VP, Haber SN, Steininger TL, Will MJ, Zhang M (2002). Opioid modulation of taste hedonics within the ventral striatum. Physiol Behav 76: 365-377.

Kirkham TC (2003). Endogenous cannabinoids: a new target in the treatment of obesity. Am J Physiol Regul Integr Comp Physiol 284: R343-344.

Kirkham TC, Williams CM (2001). Synergistic efects of opioid and cannabinoid antagonists on food intake. Psychopharmacology (Berl) 153: 267-270.

Ledent C, Valverde O, Cossu G, Petitet F, Aubert JF, Beslot F et al (1999). Unresponsiveness to cannabinoids and reduced addictive effects of opiates in CB1 receptor knockout mice. Science 283: 401-404.

Low MJ, Hayward MD, Appleyard SM, Rubinstein M (2003). State-dependent modulation of feeding behavior by proopiomelanocortin-derived beta-endorphin. Ann NY Acad Sci 994: 192-201.

Mansour A, Khachaturian H, Lewis ME, Akil H, Watson SJ (1987). Autoradiographic differentiation of $\mathrm{mu}$, delta, and kappa opioid receptors in the rat forebrain and midbrain. $J$ Neurosci 7: 2445-2464.

Manzanares J, Corchero J, Romero J, Fernandez-Ruiz JJ, Ramos JA, Fuentes JA (1999). Pharmacological and biochemical interactions between opioids and cannabinoids. Trends Pharmacol Sci 20: $287-294$.

Martin M, Ledent C, Parmentier M, Maldonado R, Valverde O (2000). Cocaine, but not morphine, induces conditioned place preference and sensitization to locomotor responses in CB1 knockout mice. Eur J Neurosci 12: 4038-4046.

Mascia MS, Obinu MC, Ledent C, Parmentier M, Bohme GA, Imperato A et al (1999). Lack of morphine-induced dopamine release in the nucleus accumbens of cannabinoid $\mathrm{CB}(1)$ receptor knockout mice. Eur J Pharmacol 383: R1-R2.

Matsuda LA, Lolait SJ, Brownstein MJ, Young AC, Bonner TI (1990). Structure of a cannabinoid receptor and functional expression of the cloned cDNA. Nature 346: 561-564. 
McLaughlin PJ, Winston K, Swezey L, Wisniecki A, Aberman J, Tardif DJ et al (2003). The cannabinoid CB1 antagonists SR 141716A and AM 251 suppress food intake and food-reinforced behavior in a variety of tasks in rats. Behav Pharmacol 14: 583-588.

Munzar P, Tanda G, Justinova Z, Goldberg SR (2004). Histamine h3 receptor antagonists potentiate methamphetamine selfadministration and methamphetamine-induced accumbal dopamine release. Neuropsychopharmacology 29: 705-717.

National Research Council (2003). Guidelines for the Care and Use of Mammals in Neuroscience and Behavioral Research. The National Academy Press: Washington, DC, USA.

Nencini P, Graziani M (1990). Opiatergic modulation of preparatory and consummatory components of feeding and drinking. Pharmacol Biochem Behav 37: 531-537.

Piomelli D (2003). The molecular logic of endocannabinoid signalling. Nat Rev Neurosci 4: 873-884.

Reisine T, Law SF, Blake A, Tallent M (1996). Molecular mechanisms of opiate receptor coupling to $G$ proteins and effector systems. Ann NY Acad Sci 780: 168-175.

Robbins TW, Watson BA, Gaskin M, Ennis C (1983). Contrasting interactions of pipradrol, D-amphetamine, cocaine, cocaine analogues, apomorphine and other drugs with conditioned reinforcement. Psychopharmacology (Berl) 80: 113-119.

Roberts DC, Bennett SA (1993). Heroin self-administration in rats under a progressive ratio schedule of reinforcement. Psychopharmacology (Berl) 111: 215-218.

Rodriguez JJ, Mackie K, Pickel VM (2001). Ultrastructural localization of the CB1 cannabinoid receptor in mu-opioid receptor patches of the rat caudate putamen nucleus. J Neurosci 21: 823-833.

Rowland NE, Mukherjee M, Robertson K (2001). Effects of the cannabinoid receptor antagonist SR 141716, alone and in combination with dexfenfluramine or naloxone, on food intake in rats. Psychopharmacology (Berl) 159: 111-116.

Salamone JD, Correa M, Mingote S, Weber SM (2003). Nucleus accumbens dopamine and the regulation of effort in foodseeking behavior: implications for studies of natural motivation, psychiatry, and drug abuse. J Pharmacol Exp Ther 305: 1-8.

Schmelzeis MC, Mittleman G (1996). The hippocampus and reward: effects of hippocampal lesions on progressive-ratio responding. Behav Neurosci 110: 1049-1066.

Simiand J, Keane M, Keane PE, Soubrie P (1998). SR 141716, a CB1 cannabinoid receptor antagonist, selectively reduces sweet food intake in marmoset. Behav Pharmacol 9: 179-181.

Solinas M, Panlilio LV, Antoniou K, Pappas LA, Goldberg SR (2003). The cannabinoid CB1 antagonist $\mathrm{N}$-piperidinyl-5-(4chlorophenyl)-1-(2,4-dichlorophenyl)-4-methylpyrazole-3-carbox- amide (SR-141716A) differentially alters the reinforcing effects of heroin under continuous reinforcement, fixed ratio, and progressive ratio schedules of drug self-administration in rats. J Pharmacol Exp Ther 306: 93-102.

Solinas M, Zangen A, Thiriet N, Goldberg SR (2004). Betaendorphin elevations in the ventral tegmental area regulate the discriminative effects of delta-9-tetrahydrocannabinol. Eur $J$ Neurosci 19: 3183-3192.

Spano MS, Fattore L, Cossu G, Deiana S, Fadda P, Fratta W (2004). CB1 receptor agonist and heroin, but not cocaine, reinstate cannabinoid-seeking behaviour in the rat. $\mathrm{Br} J$ Pharmacol 143: 343-350.

Tanda G, Goldberg SR (2003). Cannabinoids: reward, dependence, and underlying neurochemical mechanisms - a review of recent preclinical data. Psychopharmacology (Berl) 169: 115-134.

Tanda G, Pontieri FE, Di Chiara G (1997). Cannabinoid and heroin activation of mesolimbic dopamine transmission by a common mul opioid receptor mechanism. Science 276: 2048-2050.

Thornton-Jones ZD, Vickers SP, Clifton PG (2004). The cannabinoid CB1 receptor antagonist SR141716A reduces appetitive and consummatory responses for food. Psychopharmacology (Berl) (online); doi: 10.1007/s00213-004-2047-8.

Valverde O, Noble F, Beslot F, Dauge V, Fournie-Zaluski MC, Roques BP (2001). Delta9-tetrahydrocannabinol releases and facilitates the effects of endogenous enkephalins: reduction in morphine withdrawal syndrome without change in rewarding effect. Eur J Neurosci 13: 1816-1824.

Vigano D, Grazia Cascio M, Rubino T, Fezza F, Vaccani A, Di Marzo V et al (2003). Chronic morphine modulates the contents of the endocannabinoid, 2-arachidonoyl glycerol, in rat brain. Neuropsychopharmacology 28: 1160-1167.

Vigano D, Valenti M, Cascio MG, Di Marzo V, Parolaro D (2004). Changes in endocannabinoid levels in a rat model of behavioral sensitization to morphine. Eur J Neurosci 20: 1849-1857.

Williams CM, Kirkham TC (1999). Anandamide induces overeating: mediation by central cannabinoid (CB1) receptors. Psychopharmacology (Berl) 143: 315-317.

Williams CM, Kirkham TC (2002a). Observational analysis of feeding induced by Delta9-THC and anandamide. Physiol Behav 76: $241-250$

Williams CM, Kirkham TC (2002b). Reversal of delta 9-THC hyperphagia by SR141716 and naloxone but not dexfenfluramine. Pharmacol Biochem Behav 71: 333-340.

Williams CM, Rogers PJ, Kirkham TC (1998). Hyperphagia in prefed rats following oral delta9-THC. Physiol Behav 65: 343-346.

Yeomans MR, Gray RW (2002). Opioid peptides and the control of human ingestive behaviour. Neurosci Biobehav Rev 26: 713-728. 